\title{
OPTIMASI PENJADWALAN PRODUKSI MENGGUNAKAN METODE CAMPBELL DUDEK SMITH (DI PT. XYZ)
}

\author{
Fathurohman ${ }^{1}$, Muhamad Sayuti ${ }^{2}$, Alexander Lambas $\mathbf{T}^{3}$ \\ 1,2,3 Jurusan Teknik Industri, Fakultas Teknik dan Ilmu Komputer, Universitas Buana Perjuangan Karawang \\ Jl. HS. Ronggowaluyo Telukjambe Timur Karawang, \\ Email: Fathurohman @ubpkarawang.ac.id
}

\begin{abstract}
Scheduling is the allocation of limited resources to do a number of jobs. Problems arise when at certain stages of operation some or all of the work requires the same work station. PT XYZ is a service company engaged in electro plating, where the work process is carried out when receiving a request from the customer. The arrival of products from customers who are late and other things will affect the process of working on the products to be plated so that the schedule for sending back products that have been platted is not on schedule while the company does not have inventory. Therefore, a good production machine scheduling optimization will be able to produce good processing time. In addition to knowing the number of machines and jobs as well as the number and sequence of their production processes, research is also carried out by calculating the processing time of each job. Based on the comparison between the best iterations of CDS and the company's FSCS method, it is known that there is a difference in makespan time of 46990 seconds or about 13.05 hours and a flowtime difference of 216380 seconds or about 60.1 hours.
\end{abstract}

Keywords: scheduling; campbell dudek smith; makespan

\begin{abstract}
ABSTRAK
Penjadwalan adalah pengalokasian sumber daya yang terbatas untuk mengerjakan sejumlah pekerjaan. Permasalahan muncul apabila pada tahapan operasi tertentu beberapa atau seluruh pekerjaan itu membutuhkan stasiun kerja yang sama. PT XYZ merupakan perusahaan jasa yang bergerak dalam bidang elektro platting,dimana proses pengerjaan dilakukan ketika mendapat permintaan dari customer. Kedatangan produk dari customer yang terlambat dan hal yang lainnya akan mempengaruhi proses pengerjaan produk yang akan di platting sehingga jadwal pengiriman kembali produk yang sudah di platting tidak sesuai jadwal sedangkan perusahaan tidak mempunyai stok persediaan. Karena itu optimasi penjadwalan mesin produksi yang baik akan mampu menghasilkan waktu pengerjaan yang baik. Selain mengetahui jumlah mesin dan job serta jumlah dan urutan prosesnya produksinya, penelitian juga dilakukan dengan menghitung waktu proses tiap job. Berdasarkan hasil perbandingan antara iterasi terbaik CDS dengan metode FSCS perusahaan maka diketahui bahwa terdapat selisih waktu makespan sebesar 46990 detik atau sekitar 13,05 jam dan selisih waktu flowtime sebesar 216380 detik atau sekitar 60,1 jam.
\end{abstract}

Kata kunci: penjadwalan; campbell dudek smith; makespan

\section{PENDAHULUAN}

Penjadwalan merupakan suatu kegiatan merencanakan suatu aktifitas berdasarkan waktu yang telah diatur untuk tercapainya suatu kegiatan. Menurut Jay Heizer dan Barry Render (2015). Tujuan dari penentuan jadwal adalah mengalokasikan dan memprioritaskan permintaan (yang dihasilkan oleh teknik peramalan atau order konsumen lainnya) pada fasilitas yang tersedia. Penjadwalan berkaitan dengan membangun waktu penggunan sumber daya spesifik 
organisasi, yang berkaitan dengan penggunaan peralatan dan aktifitas manusia,penjadwalan terjadi pada setiap organisasi terlepas dari apapun kegiatannya (William J.Stevenson, 2015)

PT. XYZ merupakan industri jasa yang bergerak di bidang electroplating. Electroplating adalah suatu kegiatan proses melapisi metal dengan logam lain menggunakan sistem elektrolisa, dengan tujuan untuk merubah tampilan metal menjadi tampak berbeda dari tampilan aslinya serta dengan tujuan utama yaitu mengubah atau membuat kualitas permukaan suatu benda menjadi lebih baik atau lebih indah. PT. XYZ bukan merupakan perusahaan manufaktur yang membuat suatu barang melainkan perusahaan jasa yang melakukan kegiatan electroplatting dimana perusahaan tersebut menerima keuntungan atau imbalan dari jasa proses pengolahannya saja sedangkan komponen awal dan komponen hasil proses electroplatting dirakit di perusahaan lain yang melakukan proses electroplating di PT. XYZ

PT. XYZ melakukan proses electroplating berdasarkan job order dari pelanggan, Sebab itu industri jasa sangat diharapkan mampu memenuhi seluruh permintaan customer dengan segala tantangan yang ada sehingga dapat bersaing dan mampu bertahan dari ancaman perusahaan yang bergerak di bidang yang sama. Kemampuan untuk memenuhi permintaan konsumen ini tentunya harus diimbangi dengan adanya penjadwalan serta pengendalian produksi yang baik agar proses produksi dapat stabil, efisien serta mampu memenuhi permintaan pelanggan dengan tepat waktu. PT. XYZ memiliki 3 line produksi antara lain yaitu: Nickel Chrome, Zinc Barrel, dan Zinc Rack untuk memenuhi permintaaan proses plating dari customer. dari 3 line tersebut juga memiliki shift kerja yang berbeda yaitu line Nickel chrome dengan 2 shift, Zinc Barrel 2 shift, dan Zinc Rack 1 shift.

Line Zinc Barrel khususnya pada produk Cap Outer sering terjadi masalah yaitu keterlambatan delivery produk dari customer untuk dilakukan proses platting di line zinc barrel sehingga tentuya jadwal penyelesaian produksi tidak dapat terpenuhi karena produk yang akan di proses terlambat kedatangannya, namun customer mengharapkan agar hasil produk yang sudah melalui proses line Zinc barrel dapat dikirim kembali kepada customer sesuai jadwal yang sudah ditentukan sedangkan perusahaan tidak mempunyai stok WIP dan juga tentunya akan mengganggu proses platting produk lain yang dilakukan di line Zinc Barrel. Karena itu penjadwalan dengan meminimasi waktu pengerjaan (makespan) diperlukan agar batas waktu pengerjaan yang diberikan konsumen terhadap perusahaan dapat terpenuhi dan produktifitas meningkat.

Berdasarkan data proses zinc barrel pada bulan maret 2019 menunjukan bahwa produk Cap Outer merupakan produk dengan jumlah barrel yang paling banyak diminta konsumen untuk dilakuan proses pelapisan. Sedangkan produk tersebut juga merupakan produk yang sering terjadi keterlambatan pengiriman produk dari konsumen untuk dilakukan proses platting atau pelapisan, Cap Outer memiliki persentase sekitar 32,54 \% dari jumlah seluruh item produk yang di proses di line zinc barrel.

Dengan jumlah persentase yang cukup besar tersebut maka tentunya akan cukup mengganggu pekerjaan item produk yang lain apabila terjadi suatu masalah terkait delivery dan proses pengerjaan. Beberapa masalah ini yang menjadi dasar adanya rencana penelitian mengenai Penjadwalan Produksi menggunakan Campbell Dudek Smith di line Zinc Barrel PT. XYZ.

\section{METODE PENELITIAN}

\section{Lokasi Penelitian}

Penelitian ini akan dilakukan untuk menentukan penjadwalan penentuan Produksi menggunakan Campbell Dudek Smith di line Zinc di Perusahaan electroplatting yang berlokasi di Kabupaten Karawang Jawa Barat. Hal yang terkait dengan penelitian ini adalah mengenai penjadwalan penentuan produksi. 


\section{Sumber Data}

Data yang digunakan dalam penelitian ini adalah data primer dan sekunder yang diperoleh dari perusahaan electroplatting di Kabupaten Karawang. Data yang diperoleh terdiri dari hasil dari angket, interview dan observasi.

\section{Metode Pengujian}

Pada penelitian ini analisis data dimulai dengan mencari informasi terkait masalah yang ada di perusahaan atau tempat penelitian ini, kemudian pengumpulan data-data yang didapat dari hasil wawancara maupun data yang didapat dari hasil pengamatan. Data yang didapat antara lain yaitu waktu proses, waktu baku, data waktu pengerjaan.

Data-data tersebut kemudian diolah dan dianalisis dengan menggunakan microsoft excel. Data waktu proses yang didapat akan diolah menjadi suatu bentuk urutan job untuk mendapat waktu penyelesaian yang terbaik.

Metode yang digunakan dalam penelitian ini adalah metode Campbell Dudek Smith yang merupakan pengembangan dari algoritma johnson dengan membuat iterasi guna mendapatkan nilai makespan dan flowtime terbaik. Adapun langkah yang dilakukan dalam metode ini antara lain sebagai berikut:

Untuk penjadwalan $\mathrm{n}$ job terhadap $\mathrm{m}$ mesin, dilakukan algoritma Johnson sebagai berikut:

Ambil penjadwalan pertama $(k=1)$. Untuk seluruh job yang ada, carilah harga $t * i, 1$ dan $t * i, 2$ yang minimum yang merupakan waktu proses pada mesin pertama dan kedua, dimana t $\times i, 1$-ti, 1 dan $\mathrm{t} \times 1,2=\mathrm{ti}, 2$

Jika waktu minimum didapat pada mesin pertama, (misal ti,1), selanjutnya tempatkan tugas tersebut pada awal deret penjadwalan dan bila waktu minimum didapat pada mesin kedua (misal ti,2), tugas tersebut ditempatkan pada posisi akhir dari deret penjadwalan.

Pindahkanlah tugas-tugas tersebut dari daftarnya dan susun dalam bentuk deret penjadwalan. Jika masih ada job yang tersisa ulangi kembali langkah a, sebaliknya bila tidak ada lagi job yang tersisa, berarti penjadwalan telah selesai. Dengan demikian, waktu proses dari kedua mesin yaitu mesin pertama $(t \times i, 1)$ dan mesin kedua $(t i, 2)$ pada penjadwalan ke-k adalah:

$$
\mathrm{t} * \mathrm{i}, 1=\Sigma \mathrm{k} \quad \mathrm{kt}_{\mathrm{k}} \mathrm{i}, \mathrm{k}
$$

Setelah dilakukan penjadwalan kedalam 2 mesin yaitu mesin pertama (txi,1) dan mesin kedua (ti,2) maka akan didapat nilai, nilai tersebutlah yang nanti kemudian digunakan sebagai acuan dalam menentukan urutan job dalam suatu iterasi waktu proses pengerjaan.

Dari proses pembagian kedalam 2 mesin tersebut nanti akan dihasilkan suatu nilai, jika nilai terkecil ada di (m-1) maka letakkan job pada tabel iterasi bagian atas dan jika nilai terkecil ada di (m-2) maka letakkan job pada tabel iterasi bagian bawah. 


\section{HASIL DAN PEMBAHASAN}

Dalam suatu penelitian peranan dan fungsi data sangat penting dalam penunjang suatu penelitian, semakin banyak ketersediaan data pendukung yang dibutuhkan maka akan sangat membantu dalam proses pengolahan menggunakan metode yang dipilih oleh penulis dalam penyelesaian suatu permasalahan dalam penelitian .Data tersebut dimuat kedalam bentuk tabel seperti gambar berikut yang bertujuan untuk memberi gambaran tentang jumlah proses yang dilakukan dan item pekerjaan apa saja yang terdapat di line zinc barrel tersebut.

Tabel 1. Data Proses Platting dalam hitungan barrel (keranjang)

\begin{tabular}{|c|c|c|c|}
\hline \multirow[b]{2}{*}{ No } & \multicolumn{3}{|c|}{ Jumlah } \\
\hline & Job & Barel & $\%$ \\
\hline 1 & Cap outer & 643 & $32.54 \%$ \\
\hline 2 & $\mathrm{TCT}$ & 168 & $8.50 \%$ \\
\hline 3 & Cap inner & 154 & $7.79 \%$ \\
\hline 4 & Cap outer CA & 149 & $7.54 \%$ \\
\hline 5 & Adjuster & 136 & $6.88 \%$ \\
\hline 6 & NSS & 124 & $6.28 \%$ \\
\hline 7 & Spring guide & 90 & $4.55 \%$ \\
\hline 8 & Cap outer K59 & 68 & $3.44 \%$ \\
\hline 9 & Cap 053 & 62 & $3.14 \%$ \\
\hline 10 & Cap 041 & 59 & $2.99 \%$ \\
\hline 11 & Com B & 58 & $2.94 \%$ \\
\hline 12 & Cap Inner CA & 51 & $2.58 \%$ \\
\hline 13 & Braket & 47 & $2.38 \%$ \\
\hline 14 & Plat Fluid & 38 & $1.92 \%$ \\
\hline 15 & Separator & 35 & $1.77 \%$ \\
\hline 16 & SMS & 30 & $1.52 \%$ \\
\hline 17 & Door Trim & 22 & $1.11 \%$ \\
\hline 18 & Inner Honda & 6 & $0.30 \%$ \\
\hline 19 & Com A 125 & 5 & $0.25 \%$ \\
\hline 20 & Plat B Fiting & 5 & $0.25 \%$ \\
\hline 21 & Plat Batrey & 5 & $0.25 \%$ \\
\hline 22 & Shaft L & 5 & $0.25 \%$ \\
\hline 23 & Holder Cable & 4 & $0.20 \%$ \\
\hline 24 & Pivot & 4 & $0.20 \%$ \\
\hline 25 & Cap Outer Honda & 2 & $0.10 \%$ \\
\hline 26 & NSS New & 2 & $0.10 \%$ \\
\hline 27 & Seat Spring & 3 & $0.15 \%$ \\
\hline 28 & Footrest & 1 & $0.05 \%$ \\
\hline & $\begin{array}{c}\text { Jumlah barel yang } \\
\text { diplating }\end{array}$ & 1,976 & $100 \%$ \\
\hline
\end{tabular}


Dari gambar histogram yang diambil dari data jumlah proses platting bulan Maret 2019, bahwa Cap Outer merupakan produk atau job yang paling banyak menerima orderan proses platting

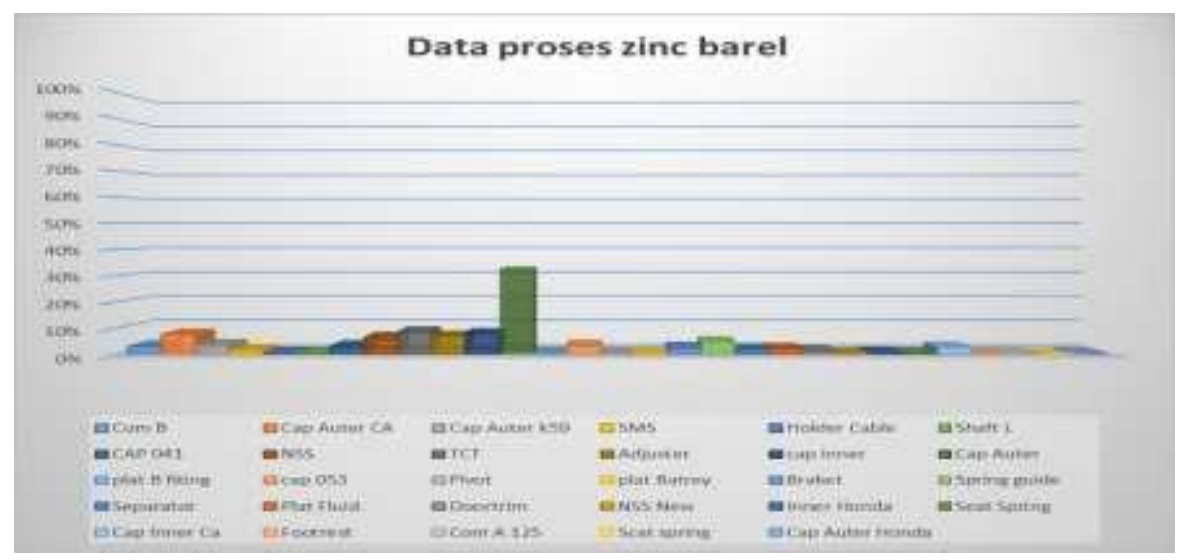

Gambar 1. Histogram Proses bulan Maret 2019.

Setelah melihat 9 job/item tertinggi atau terbanyak maka dari job-job tersebut dilakukan pengambilan data waktu proses dari 9 job tersebut, tabel waktu proses tersebut dapat dilihat dari tabel yang ada dihalaman selanjutnya.

Tabel 2. Hasil Pengamatan waktu Proses

\begin{tabular}{|c|c|c|c|c|c|c|c|c|c|c|c|c|c|c|c|}
\hline & \multirow{2}{*}{ Job } & \multicolumn{14}{|c|}{ Work Stasiun } \\
\hline & & Loading & Deggreasing & Water Rinsing & Pickling & Water Rinsing & Tinc Plating & Water Rinsing & Activasi & Water Rining & Chromating & Water Rinsing & Hot Water Rinsing & Drying & Unloading \\
\hline A & Cap Outer & 170 & 600 & 300 & 420 & 90 & 4800 & 20 & 60 & 20 & 20 & 20 & 15 & 600 & 80 \\
\hline B & Cap Inner & 180 & 600 & 350 & 420 & 60 & 3600 & 20 & 60 & 20 & 20 & 15 & 15 & 550 & 80 \\
\hline C & $\begin{array}{c}\text { Cap Outer K } \\
59\end{array}$ & 160 & 600 & 240 & 420 & 75 & 4800 & 15 & 60 & 15 & 30 & 20 & 10 & 580 & 85 \\
\hline D & Spring guide & 120 & 600 & 120 & 300 & 90 & 3000 & 25 & 60 & 25 & 30 & 15 & 15 & 600 & 70 \\
\hline E & $\mathrm{TCT}$ & 155 & 600 & 300 & 300 & 120 & 3000 & 25 & 60 & 25 & 30 & 15 & 10 & 600 & 90 \\
\hline F & Adjuster & 165 & 450 & 240 & 300 & 120 & 3000 & 30 & 60 & 30 & 15 & 20 & 15 & 550 & 80 \\
\hline G & NSS & 150 & 450 & 120 & 360 & 90 & 2700 & 15 & 60 & 15 & 20 & 15 & 20 & 560 & 90 \\
\hline $\mathrm{H}$ & Cap Outer CA & 175 & 600 & 120 & 420 & 120 & 4800 & 20 & 60 & 20 & 20 & 20 & 15 & 600 & 80 \\
\hline I & Cap 053 & 145 & 600 & 240 & 420 & 90 & 3000 & 15 & 60 & 15 & 15 & 15 & 10 & 600 & 75 \\
\hline & & WS 1 & WS2 & WS 3 & WS 4 & WS 5 & WS 6 & WS7 & WS 8 & WS9 & WS 10 & WS 11 & WS 12 & $\begin{array}{l}\text { WS } \\
13\end{array}$ & WS 14 \\
\hline
\end{tabular}

Keterangan: huruf alfabet diatas akan digunakan sebagai pengganti nama item job

Setelah didapat data waktu proses dari hasil pengamatan maka selanjutnya akan dicari data berdasarkan metode yang digunakan perusahaan, adapun data tersebut dapat kita lihat pada tabel 3 
Tabel 3. Waktu penjadwalan dengan FCFS

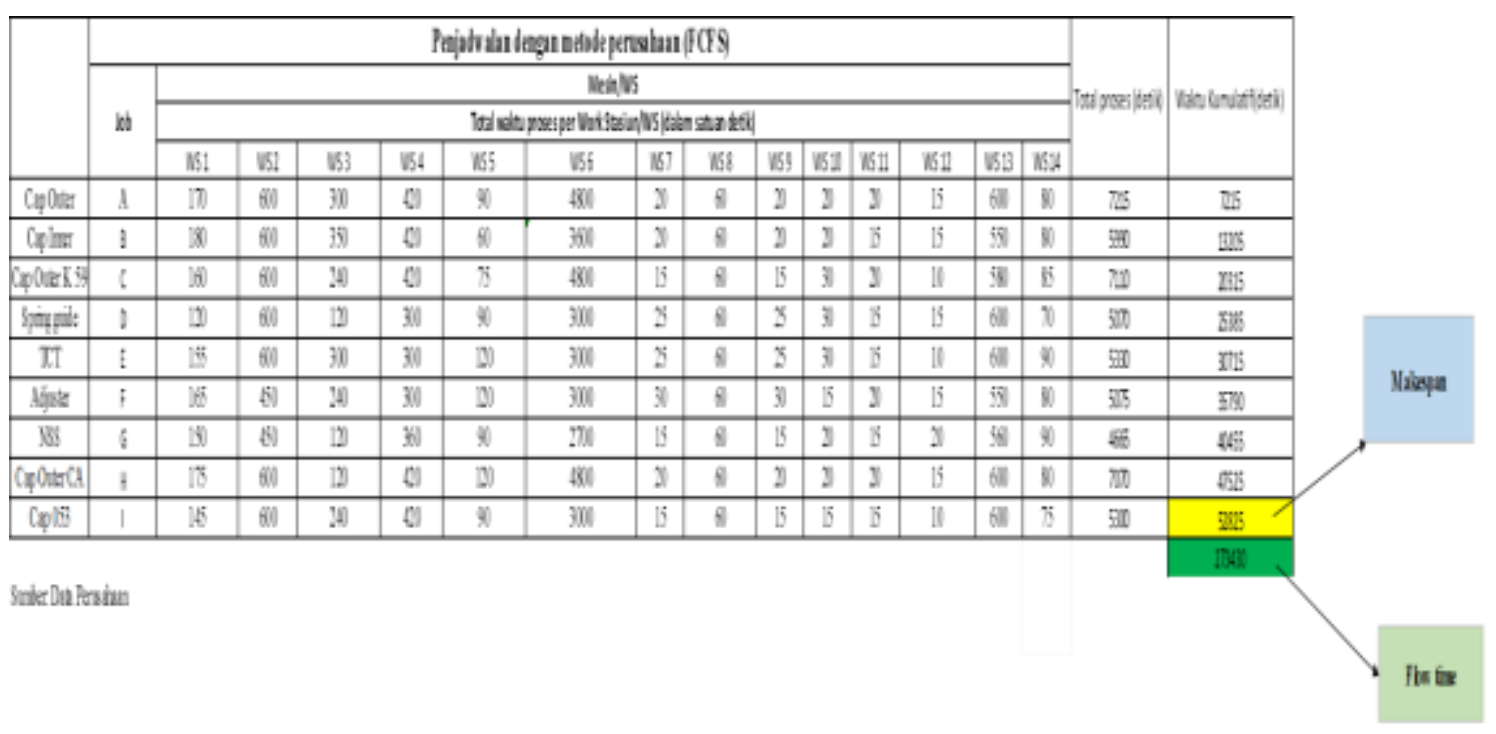

Berdasarkan rumus $\mathrm{K}=\mathrm{M}-1$ maka total iterasi yang akan diambil yaitu 13 iterasi karena total Work Stasiun ada 14 dan jika dikurangi 1 berdasarkan rumus maka iterasi yang dibuat berjumlah 13 iterasi

Nilai (M-1) diambil dari nilai WS 1 sedangkan nilai (M-2) diambil dari WS terakhir atau WS 14, kemudian dari hasil tersebut akan diambil nilai terkecil untuk digunakan pada perhitungan total nilai waktu proses tiap iterasi. Jika nilai terkecil berada pada M-1 maka job tersebut diletakan pada urutan dari atas sedangkan jika nilai terkecil tedapat pada M-2 maka job tersebut diletakan pada urutan job dari bawah

Tabel 4 Total Waktu Proses CDS Iterasi 1

\begin{tabular}{|c|c|c|c|c|c|c|c|c|c|c|c|c|c|c|}
\hline \multicolumn{15}{|c|}{ Total waktu proses Iterasi pertama CDS } \\
\hline \multirow{3}{*}{ Jeb } & \multicolumn{14}{|c|}{ MesianIS } \\
\hline & \multicolumn{14}{|c|}{ Total rakteposes (detî) } \\
\hline & WS1 & WS 2 & W5 3 & W54 & WS5 & W5 6 & WS 7 & W58 & W59 & WS 10 & WS 11 & W5 12 & WS 13 & NS14 \\
\hline G & 150 & 600 & 720 & 1080 & 1170 & 3670 & 3885 & 3945 & 3960 & 3960 & 3995 & 4015 & 4575 & 4665 \\
\hline ⿷ & 306 & 965 & 1206 & 1506 & 1625 & 4625 & 4650 & 4710 & 4735 & 4765 & 4780 & 4790 & 5990 & 5480 \\
\hline c & 455 & 1065 & 1366 & 178 & 1890 & 6600 & 6615 & 6675 & 6690 & 6720 & 6740 & 6750 & 7330 & 7415 \\
\hline$f$ & 630 & 1000 & 1320 & 1680 & 1740 & 4740 & 4770 & 4830 & 4850 & 4875 & 4895 & 4910 & 5450 & 5540 \\
\hline$A$ & 80 & 1000 & 1700 & 2130 & 2210 & 7010 & 7030 & 7090 & 7110 & 7130 & 7150 & 7165 & 7765 & 7845 \\
\hline$H$ & 975 & 1575 & 1695 & 2115 & 2235 & 7065 & 7065 & 7115 & 7135 & 7155 & 7175 & 7190 & 7790 & 7810 \\
\hline B & 1155 & 185 & 2106 & 258 & 2685 & 6185 & 6015 & 6265 & 6265 & 6366 & 6320 & 6335 & $6 \mathrm{WS}$ & 6965 \\
\hline 1 & 1900 & 1900 & 2140 & 2560 & 2650 & 3650 & 5665 & 572 & 5740 & 5735 & 5770 & 5780 & 6360 & 6453 \\
\hline 0 & 1480 & 2500 & 260 & 2560 & 2740 & 8650 & 5690 & 5785 & 5765 & 5785 & 5785 & 5795 & 6960 & 6525 \\
\hline & & & & & & & & & & & & & & 6585 \\
\hline & & & & & & & & & & & & flow & & $\$ 9800$ \\
\hline
\end{tabular}

Nilai waktu proses yang terdapat di tabel di peroleh dari nilai dari hasil pengamatan waktu proses yang dilakukan sebelumnya yaitu dengan cara menjumlahkan Kumulatif nilai yaitu Kumultif di Baris 1 dan juga Kumulatif di Kolom 1, lalu setelah itu dilakukan penjumlahan kumulatif baris 2 dan seterusnya sampai baris ke 8. Penjumlahan kumulatif tersebut dilakuan dengan tetap memgambil nilai dari hasil pengamatan waktu proses dalam penjumlahan kumulatifnya. Untuk nilai pada job terakhir atau baris ke 9 dilakukan perhitungan yang berbeda yaitu dengan cara menjumlahkan nilai dari kolom 8 dengan nilai kolom job terakhir untuk mengisi nilai di baris 9. Nilai makespan yang muncul didapat dari nilai job terakhir dan work stasiun terakhir, sedangkan total flow time dari penjumlahan kumulatif seluruh nilai yang ada di stasiun terakhir yang sebelumnya telah dilakukan perhitungan setiap barisnnya. Dari CDS ke 8 maka didapat urutan iterasi yaitu job atau produk E-D-H-A- C-I-F-G-B, urutan iterasi diperoleh dari hasil perhitungan berdasarkan metode CDS. Untuk nilai ( M-1) diperoleh dari dari penjumlahan nilai di WS 1+WS 2+WS 3+WS 4+ WS 5+WS 6+WS 7 sedangkan nilai (M-2) dari penjumlahan nilai WS 8+WS 9+WS 10+WS 11+WS 12+WS 13+WS 14 
Tabel 5. Total waktu proses CDS Iterasi 8

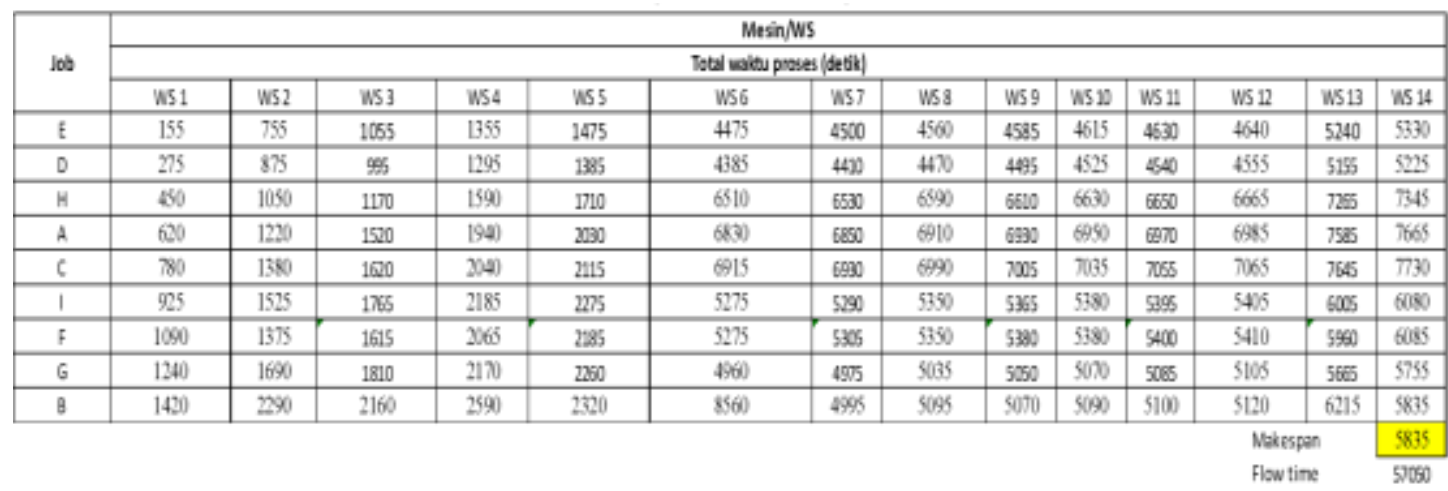

Tabel 6. Penjadwalan CDS Iterasi 13 Iiterasi ketigabelas CDS

\begin{tabular}{|c|c|c|}
\hline \multirow{2}{*}{ Job } & \multicolumn{2}{|c|}{ Mesinf WS } \\
\cline { 2 - 3 } & Total waktu proses (detik) \\
\cline { 2 - 3 } & M-1 & M-2 \\
\hline A & 7135 & 7045 \\
\hline B & 5910 & 5810 \\
\hline C & 7025 & 6950 \\
\hline D & 5000 & 4950 \\
\hline E & 5240 & 5175 \\
\hline F & 4995 & 4910 \\
\hline G & 4575 & 4515 \\
\hline H & 6990 & 6895 \\
\hline I & 5225 & 5155 \\
\hline
\end{tabular}

Tabel 7 Total Waktu Proses CDS Iterasi 1

\begin{tabular}{|c|c|c|c|c|c|c|c|c|c|c|c|c|c|c|}
\hline \multirow{3}{*}{ Jet } & \multicolumn{14}{|c|}{ Mesin/W5 } \\
\hline & \multicolumn{14}{|c|}{ Total wakts preses (det) } \\
\hline & W51 & W52 & W53 & W54 & W55 & W56 & W57 & W58 & w59 & WS 12 & W5 11 & ws 12 & w5 13 & W5 14 \\
\hline$A$ & 170 & 770 & 100 & 1491 & 1500 & 6331 & 6000 & 6460 & 6430 & 6560 & 6520 & 6535 & 7135 & 7215 \\
\hline$c$ & 330 & 930 & 110 & 1991 & 1665 & $6+65$ & 600 & $6 \$ 40$ & 6555 & 6585 & 6606 & 6615 & 785 & 7230 \\
\hline$H$ & 566 & 1105 & 128 & 1645 & $1 \pi 5$ & 6855 & 6505 & 6645 & $6 \ldots 5$ & 6685 & $6 \pi 6$ & 6730 & 7300 & 7420 \\
\hline 8 & 686 & 1285 & 1685 & 2005 & 2115 & 5715 & 5735 & 5795 & 585 & 8335 & 5850 & 5865 & 6415 & 6495 \\
\hline E & 340 & 1441 & 1740 & 2041 & 2160 & 5160 & $5: 85$ & 5245 & 520 & 5360 & 5315 & 538 & gax & 6015 \\
\hline 1 & 985 & 1585 & 138 & 2245 & $22 a 5$ & 5335 & 520 & 5410 & 505 & 5440 & 545 & 5465 & 6035 & 6140 \\
\hline 0 & 11115 & 1705 & 188 & 2125 & 2215 & 5215 & 5200 & 5360 & 5225 & 5355 & 5370 & 5388 & 535 & 6055 \\
\hline $\mathrm{F}$ & 127 & 1721 & 1920 & 2261 & 200 & 5380 & 5410 & 5470 & 5500 & 5515 & 555 & 5590 & 620 & 6130 \\
\hline 6 & 1421 & 2170 & $2(9)$ & 2621 & 2470 & 8031 & 5425 & 5530 & 5515 & 5535 & 5590 & 5570 & $6(6)$ & 6270 \\
\hline & & & & & & & & & & & & & & 20 \\
\hline
\end{tabular}




\section{Tabel 8. Rangkuman Iterasi CDS}

\begin{tabular}{|c|c|c|}
\hline Iterasi & $\begin{array}{c}\text { Makespan } \\
\text { (detik) }\end{array}$ & $\begin{array}{c}\text { Flowtime } \\
\text { (detik) }\end{array}$ \\
\hline 1 & 6525 & 58760 \\
\hline 2 & 8270 & 59535 \\
\hline 3 & 6230 & 57435 \\
\hline 4 & 6230 & 57480 \\
\hline 5 & 6230 & 57450 \\
\hline 6 & 6230 & 57345 \\
\hline 7 & 6230 & 57345 \\
\hline 8 & 5835 & 57050 \\
\hline 9 & 6270 & 59045 \\
\hline 10 & 6515 & 59310 \\
\hline 11 & 6270 & 59060 \\
\hline 12 & 6525 & 61645 \\
\hline 13 & 6270 & 59050 \\
\hline Waktu & 5835 & 57050 \\
\hline terendah & & \\
\hline
\end{tabular}

Dari hasil rangkuman 13 iterasi menggunakan metode CDS diketahui bahwa iterasi terbaik di dapat dari iterasi ke 8 yaitu dengan makespan 5835 detik atau sekitar 1,62 jam dan flow time 57050 detik atau sekitar 15,847 jam

Tabel 9. Perbandingan FCFS dengan CDS

\begin{tabular}{|c|c|c|}
\hline & FSCS & CDS \\
\hline Makespan & 52825 & 5835 \\
\hline Flowtime & 273430 & 57050 \\
\hline
\end{tabular}

Berdasarkan hasil perbandingan antara iterasi terbaik CDS dengan metode FSCS perusahaan maka diketahui bahwa terdapat selisih waktu makespan sebesar 46990 detik atau sekitar 13,05 jam dan selisih waktu flowtime sebesar 216380 detik atau sekitar 60,1 jam. Dengan demikian diketahui bahwa metode CDS mampu menghemat waktu makespan sebesar 46990 detik atau sekitar 13,05 jam dan juga flowtime sebesar 216380 detik atau sekitar 60,1 jam.

\section{KESIMPULAN}

Dari hasil analisa yang dilakukan terkait dengan Optimasi penjadwalan produksi menggunakan metode Campbell Dudek Smith dapat ditarik kesimpulan sebagai berikut :

1. Metode Campbel Dudek Smith dapat diterapkan dalam penjadwalan operasi mesin di perusahaan jasa elektroplatting bukan hanya dapat digunakan dalam operasi mesin perusahaan manufaktur yang bersifat make to stock tapi juga dapat diterapkan pada perusahaan yang menjalankan operasinya berdasarkan sistem job order

2. Berdasarkan hasil penelitian diketahui bahwa CDS mampu memberikan penjadwalan yang lebih optimal dibandingkan yang ada pada perusahaan, terutama ketika terjadi urgent akibat dari telat datangnya produk dari customer untuk dilakukan proses pelapisan atau platting yang tentunya akan mengakibatkan terlambatnya juga pengiriman produk yang sudah di platting tersebut untuk dikirim kembali kepada customer tersebut. Dari seluruh job yang ada di line zinc barrel, diambil 9 job tertinggi atau 9 job yang paling sering dilakukan proses pelapisan di line tersebut, 9 job tersebut dilihat berdasarkan jumlah barrel (bak keranjang) yang di proses. Berdasarkan hasil iterasi CDS 9 job tersebut diketahui bahwa dapat menghemat makespan sebesar sebesar 46990 detik dan juga flowtime sebesar 216380 detik

3. Dengan hal tersebut maka CDS dapat diterapkan di perusahaan tersebut untuk mengurangi keterlambatan produk Cap Outer yang sering terjadi telat delivery dari customer dan juga dapat diterapkan untuk mengoptimasi penjadwalan pekerjaan yang lain yang ada di line zinc barrel dengan memperhatikan job-job tersebut berdasarkan metode CDS 


\section{DAFTAR PUSTAKA}

Heizer Jay \& Render Barry. (2017). Manajemen operasi manajemen keberlangsungan dan rantai pasokan. Jakarta: Salemba Empat

Stevenson, J. William. (2015). Operations Management Twelfth Edition. New York: McGraw-Hill Education 